\title{
Financial Crisis and the Informational Shifts: New Evidence from Sticky Information Phillips Curve
}

\begin{abstract}
We utilize the nonlinear least squares (NLLS) and seemingly unrelated regression (SUR) techniques to estimate information stickiness parameter $\lambda$ for the USA. We find that $\lambda$ values appeared in a somewhat humped shape or inverted $U$ pattern during the financial crisis. Prior to the financial crisis (1978.Q1-2006.Q4), $\lambda$ was around 0.3. However, when the sample is extended to include the financial crisis period (1978.Q1-2011.Q4), $\lambda$ increased to around 0.6. Results imply that during the financial crisis many firms became flexible and efficient and used updated information to set optimal prices.
\end{abstract}

Keywords: Financial crisis; Sticky information Phillips curve; Stickiness parameter 


\section{Introduction}

Investigating the empirical validity of the sticky information Phillips curve (SIPC) is pertinent for monetary policy. Particularly, the degree of information stickiness tends to influence the inflation dynamics. Mankiw and Reis (2002, 2003, 2006), among others, argue that models in which agents update their information occasionally rather than instantaneously resolve some stylized business cycle puzzles. According to them, models with sticky information (SI) instead of sticky prices (SP) can explain the observed facts better. Information relevant to firms' pricing decisions diffuses slowly in the economy. Therefore, when choosing prices, firms may not immediately update their old information because there are costs associated with collecting new information. There exists a growing literature on the SIPC, for example see Carroll (2003), Pickering (2004), Khan and Zhu (2006), Kiley (2007), Laforte (2007), Klenow and Willis (2007), Dopke et al. (2008a, 2008b), Korenok (2008), Arslan (2010), Coibion (2010) and Carrera (2012). One of the problems plaguing this literature is that none of the studies investigate the information stickiness parameter $\lambda$ considering the effects of the 2008-09 financial crisis. The ongoing obstacles due to the financial crisis continue to impede the economic recovery. An unprecedented number of firms have been intertwined in this crisis and it is therefore vital to ascertain what fraction of firms acquired updated information to set prices optimally in this period of uncertainty. This paper attempts to fill this gap by employing quarterly data over the period 1978.Q1-2011.Q4 for the USA. Utilizing the nonlinear least squares (NLLS) and seemingly unrelated regression (SUR) techniques, we estimate $\lambda$ over two sample periods: $i$. prior to the crisis (1978.Q1-2006.Q4) and ii. including the crisis (1978.Q1-2011.Q4). In addition, we estimate $\lambda$ by adding a quarter sequentially from 2007.Q1 to 2011.Q4 to precisely determine when the estimate of $\lambda$ starts to change during the crisis period.

The innovative aspect in this paper is that we explore the informational shifts in the economy. In doing so, we investigate how the recent financial crisis influenced the frequency of information updates by firms. We find that $\lambda$ values appeared in a somewhat humped shape or inverted $U$ pattern during the financial crisis. Prior to the financial crisis (1978.Q1-2006.Q4), $\lambda$ was around 0.3. However, when the sample is extended to include the financial crisis period (1978.Q1-2011.Q4), $\lambda$ increased to around 0.6. The estimate of $\lambda$ until 2007.Q4 was around 0.5, however it rapidly increased to around 0.8 when the sample is extended up to 2009.Q2. Samples beyond 2009.Q2 reveal that $\lambda$ started to decline, albeit still higher than the estimate in pre-crisis 
period. These results imply that during the recent financial crisis many firms became flexible and efficient and used updated information to set optimal prices. Rational individuals will pursue this strategy so that they sustain their market share. Perhaps the costs associated with information updates during the crisis were lower.

The outline of this paper is as follows. Section 2 presents the specification of the SIPC. Section 3 provides the empirical results. Section 4 concludes.

\section{Mankiw and Reis Model}

Our specification of the SIPC is adapted from Mankiw and Reis (2002). They assume that firms take time to assimilate information to form expectations. In each period, only a fraction $\lambda$ of firms gathers the up-to-date information about the current state of the economy and re-computes and adjusts the optimal path of future prices. This proportion of firms is efficient and uses the current information to form expectations. Remaining (1- $\lambda)$ firms continue using their previous plans and set prices based on outdated information. These firms need different lengths of time to use the available information. Mankiw and Reis derive the following version of the SIPC:

$$
\pi_{t}=\frac{\lambda \alpha}{(1-\lambda)} y_{t}+\lambda \sum_{j=0}^{\infty}(1-\lambda)^{j} E_{t-1-j}\left(\pi_{t}+\alpha \Delta y_{t}\right)
$$

where $\pi=$ rate of inflation, $y=$ output gap and $E=$ expected value. The parameter $\alpha$ measures the sensitivity of the optimal relative price to the current output gap and depends on the structure of the economy, for example preferences, technology, market structures etc. According Ball and Romer (1990), the parameter $\alpha$ can be interpreted as a measure of the degree of real rigidity.

\section{Empirical Results}

\section{Data and Unit Roots}

We use quarterly data over the period 1978.Q1-2011.Q4 for the USA. The real output (GDP) gap is computed using the Hodrick-Prescott (1997) (HP) filter with a smoothing parameter of 1600. For the purpose of robustness in the results, we also utilize the Baxter- King (1999) (BK) and Christiano and Fitzgerald (2003) (CF) filtering methods. For experts' inflation and output forecasts, we follow Carroll (2003) and use the survey data provided by Survey of Professional 
Forecasters. The actual GDP and inflation series are attained from OECD's Main Economic Indicators database.

We tested for unit roots in $\pi$ and $y$ using the Carrion-i-Silvestre et al. (2009) technique. This procedure allows for multiple structural breaks in the level and/or slope of the trend function under both the null and alternative hypotheses. Carrion-i-Silvestre et al. (2009) consider the feasible point optimal statistic of Elliott et al. (1996) and the class of $M$-tests introduced in Stock (1999) and analyzed in Ng and Perron (2001). The feasible point optimal statistic is given by:

$$
P_{T}^{g l s}\left(\lambda^{0}\right)=\left\{S\left(\bar{\alpha}, \lambda^{0}\right)-\bar{\alpha} S\left(1, \lambda^{0}\right)\right\} / s^{2}\left(\lambda^{0}\right)
$$

where $\lambda$ is the estimate of the break fraction, $\bar{\alpha}=1+\bar{c} / T(\bar{c}$ is the noncentrality parameter $)$ and $s^{2}\left(\lambda^{0}\right)$ is an estimate of the spectral density at frequency zero of $v_{t}$. The M-class of tests is defined by:

$$
\begin{aligned}
& M Z^{G L S}\left({ }^{0}\right)=\left(\begin{array}{llll}
T^{1} & \tilde{y}_{T}^{2} & s( & \left.{ }^{0}\right)^{2}
\end{array}\right)\left(\begin{array}{lll}
2 T^{2} & \sum_{t=1}^{T} \tilde{y}_{t \quad 1}^{2}
\end{array}\right)^{1} \\
& \operatorname{MSB}^{G L S}\left({ }^{0}\right)=\left(s\left({ }^{0}\right)^{2} T^{2} \sum_{t=1}^{T} \tilde{y}_{t \quad 1}^{2}\right)^{1 / 2} \\
& M Z_{t}^{G L S}\left({ }^{0}\right)=\left(\begin{array}{llll}
T^{1}{ }^{1} \tilde{y}_{T}^{2} & s( & \left.{ }^{0}\right)^{2}
\end{array}\right)\left(4 s\left({ }^{0}\right)^{2} T^{2} \sum_{t=1}^{T} \tilde{y}_{t 1}^{2}\right)^{1 / 2}
\end{aligned}
$$

with $\tilde{y}_{t}=y_{t} \wedge^{\prime} z\left({ }_{t}^{0}\right)$, where $\hat{\psi}$ minimizes the objective function (see equation 4 in Carrion-i-Silvestre et al., 2009, p. 1759). For the definition of $s\left(\lambda^{0}\right)^{2}$, see equation 6 in Carrioni-Silvestre et al. (2009, p. 1759). Another statistic is a modified feasible point optimal test defined by:

$$
M P_{T}^{G L S}\left({ }^{0}\right)=\left[c^{2} T^{2} \sum_{t=1}^{T} \tilde{y}_{t 1}^{2}+\left(\begin{array}{lll}
1 & \bar{c}
\end{array}\right) T^{1} \tilde{y}_{t}^{2}\right] / s\left({ }^{0}\right)^{2}
$$


Table 1 presents the unit root test results for $P_{T}^{g l s}\left(\lambda^{0}\right), \operatorname{MZ}_{\alpha}^{G L S}\left(\lambda^{0}\right), \operatorname{MSB}^{G L S}\left(\lambda^{0}\right)$, $M Z_{t}^{G L S}\left(\lambda^{0}\right)$ and $M P_{T}^{G L S}\left(\lambda^{0}\right)$. We test for a We test for a maximum of 4 structural breaks when deterministic time trend is included in the test regressions. The test results point to trend stationary processes in $\pi$ and $y$. The test statistics are less negative than the critical values implying that the unit root null can be rejected at the 5\% level. The endogenous break dates yield by each test is plausible; most breaks correspond to the 2007-08 financial crisis. Possibly other break dates such as 1991.Q2, 1981.Q4, 1990.Q3, 1990.Q4, 2000.Q2, 2001.Q3, 1982.Q2 and 2001.Q4 highlight the occurrence of recessions in the USA.

Table 1: Carrion-i-Silvestre et al. (2009) unit root test, 1978.Q1-2011.Q4

\begin{tabular}{|c|c|c|c|}
\hline Test and Vari & & $\begin{array}{l}\text { Test Statistic } \\
\text { (Critical Value) }\end{array}$ & Break Dates \\
\hline$P_{T}^{g l s}\left(\lambda^{0}\right)$ & $\begin{array}{l}y \\
\pi\end{array}$ & $\begin{array}{l}-17.031(-11.119) \\
-19.239(-15.935)\end{array}$ & $\begin{array}{l}\text { 1991.Q2; 2007.Q1; 2007.Q4; 2008.Q3 } \\
\text { 1981.Q4; 2007.Q2; 2007.Q3; 2007.Q4 }\end{array}$ \\
\hline$M Z_{\alpha}^{G L S}\left(\lambda^{0}\right)$ & $\begin{array}{l}y \\
\pi\end{array}$ & $\begin{array}{l}-12.220(-8.112) \\
-15.701(-9.473) \\
\end{array}$ & $\begin{array}{l}\text { 1990.Q3; 2007.Q2; 2007.Q4; 2008.Q1 } \\
\text { 1990.Q4; 2006.Q4; 2007.Q1; 2007.Q2 }\end{array}$ \\
\hline$M S B^{G L S}\left(\lambda^{0}\right)$ & $\begin{array}{l}y \\
\pi\end{array}$ & $\begin{array}{l}-21.003(-16.230) \\
-32.272(-25.114)\end{array}$ & $\begin{array}{l}\text { 2000.Q2; 2007.Q1; 2007.Q3; 2008.Q1 } \\
\text { 2001.Q3; 2007.Q2; 2007.Q3; 2007.Q4 }\end{array}$ \\
\hline$M Z_{t}^{G L S}\left(\lambda^{0}\right)$ & $\begin{array}{l}y \\
\pi\end{array}$ & $\begin{array}{l}-11.060(-10.984) \\
-10.120(-5.456)\end{array}$ & $\begin{array}{l}\text { 1982.Q2; 2007.Q1; 2007.Q3; 2008.Q1 } \\
\text { 2001.Q4; 2006.Q4; 2007.Q1; 2007.Q2 }\end{array}$ \\
\hline$M_{T}^{G L S}\left(\lambda^{0}\right)$ & $\begin{array}{l}y \\
\pi\end{array}$ & $\begin{array}{l}-25.731(-22.701) \\
-4.203(-3.250)\end{array}$ & $\begin{array}{l}\text { 2007.Q1; 2007.Q2; 2007.Q4；2008.Q1 } \\
\text { 2007.Q2; 2007.Q3；2007.Q4; 2008.Q1 }\end{array}$ \\
\hline
\end{tabular}

\section{NLLS and SUR Estimates}

Following the work of Dopke et al. (2008a, 2008b), we estimate $\lambda$ using the NLLS and SUR methods. We make two assumptions that are considered plausible in the literature. First, the updating firms in each period consider professional forecasts to form rational expectations of inflation and output gap up to six quarters ahead. To this end, the infinite sum in (1) is truncated at three to six lags. Second, we impose the restriction that $\alpha$ lies between 0.10 and 0.20 ; see Mankiw and Reis (2002), Khan and Zhu (2006) and Dopke et al. (2008a, 2008b).

The SUR method accounts for the disturbance correlation across equations. The advantage of using this method is that it does not require any instruments. In our case, it is difficult to argue that the SUR method yields more efficient estimates than the NLLS because the estimates in both are fairly consistent. We estimate $\lambda$ for two periods: i. excluding the financial crisis (1978.Q1-2006.Q4) and ii. including the financial crisis (1978.Q1-2011.Q4). Tables 2 and 3 
display $\lambda$ estimates of NLLS and SUR, respectively. The HP filtered output gap is employed. Given that there exist significant structural breaks in $\pi$ and $y$, therefore we integrate dummies in the regression equations (see Tables 2 and 3 for details).

\section{Table 2: SIPC Regressions: Nonlinear Least Squares}

\begin{tabular}{|c|c|c|c|c|c|c|c|c|}
\hline & \multicolumn{4}{|c|}{$\begin{array}{l}\text { Stickiness Parameter } \lambda: \\
\text { Excluding the Financial Crisis Period }\end{array}$} & \multicolumn{4}{|c|}{$\begin{array}{l}\text { Stickiness Parameter } \lambda \text { : } \\
\text { Including the Financial Crisis Period }\end{array}$} \\
\hline $\begin{array}{l}\text { Truncation } \\
\text { at lag: }\end{array}$ & 3 & 4 & 5 & 6 & 3 & 4 & 5 & 6 \\
\hline$\alpha=0.10$ & $\begin{array}{l}0.340 \\
(2.37)^{* *}\end{array}$ & $\begin{array}{l}0.336 \\
(3.25)^{* * *}\end{array}$ & $\begin{array}{l}0.328 \\
(4 \cdot 36)^{* * *}\end{array}$ & $\begin{array}{l}0.323 \\
(3.50)^{* * *}\end{array}$ & $\begin{array}{l}0.647 \\
(6.73)^{* * *}\end{array}$ & $\begin{array}{l}0.640 \\
(8.29)^{* * *}\end{array}$ & $\begin{array}{l}0.619 \\
(6.28)^{* * *}\end{array}$ & $\begin{array}{l}0.615 \\
(6.75)^{* * *}\end{array}$ \\
\hline$\alpha=0.15$ & $\begin{array}{l}0.338 \\
(6.52)^{* * *}\end{array}$ & $\begin{array}{l}0.322 \\
(3.46)^{* * *}\end{array}$ & $\begin{array}{l}0.316 \\
(3 \cdot 30)^{* * *}\end{array}$ & $\begin{array}{l}0.315 \\
(5 \cdot 54)^{* * *}\end{array}$ & $\begin{array}{l}0.647 \\
(4.56)^{* * *}\end{array}$ & $\begin{array}{l}0.594 \\
(6.70)^{* * *}\end{array}$ & $\begin{array}{l}0.586 \\
(5.64)^{* * *}\end{array}$ & $\begin{array}{l}0.585 \\
(4.90)^{* * *}\end{array}$ \\
\hline$\alpha=0.20$ & $\begin{array}{l}0.339 \\
(4.48)^{* * *}\end{array}$ & $\begin{array}{l}0.307 \\
(2.47)^{* *}\end{array}$ & $\begin{array}{l}0.260 \\
(7.19)^{* * *}\end{array}$ & $\begin{array}{l}0.256 \\
(4.70)^{* * *}\end{array}$ & $\begin{array}{l}0.642 \\
(8.82)^{* * *}\end{array}$ & $\begin{array}{l}0.640 \\
(7.93)^{* * *}\end{array}$ & $\begin{array}{l}0.628 \\
(8.17)^{* * *}\end{array}$ & $\begin{array}{l}0.617 \\
(4.53)^{* * *}\end{array}$ \\
\hline $\begin{array}{l}\text { Dummies } \\
\text { Included }\end{array}$ & \multicolumn{4}{|c|}{ DUM1982; DUM1991; DUM2001 } & \multicolumn{4}{|c|}{ DUM1982; DUM1991; DUM2001; DUMFC } \\
\hline $\begin{array}{l}\text { Time } \\
\text { Period }\end{array}$ & \multicolumn{4}{|c|}{ 1978.Q1-2006.Q4 } & \multicolumn{4}{|c|}{ 1978.Q1-2011.Q4 } \\
\hline \multicolumn{9}{|c|}{$\begin{array}{l}\text { Notes: t-statistics are reported in parentheses. }{ }^{* * *} \text { and }{ }^{* *} \text { denotes statistical significance at } 1 \% \text { and } 5 \% \text { levels, } \\
\text { respectively. DUM1982, DUM1991, DUM2001 and DUMFC are dummy variables. The former three dummies capture } \\
\text { the impacts of recession. DUM1982 is constructed as } 1 \text { from 1981.Q2 to 1982.Q4 and o otherwise, DUM1991 is } \\
\text { constructed as } 1 \text { from 1990.Q2 to 1991.Q4 and o otherwise and DUM2001 is constructed as } 1 \text { from 2001.Q2 to } \\
\text { 2001.Q4 and o otherwise. DUMFC captures the impact of the recent financial crisis and is constructed as } 1 \text { from } \\
\text { 2007.Q1 to 2011.Q4 and o } \\
\text { otherwise. }\end{array}$} \\
\hline
\end{tabular}

Table 3: SIPC Regressions: Seemingly Unrelated Regressions

\begin{tabular}{|c|c|c|c|c|c|c|c|c|}
\hline & \multicolumn{4}{|c|}{$\begin{array}{l}\text { Stickiness Parameter } \lambda \text { : } \\
\text { Excluding the Financial Crisis Period }\end{array}$} & \multicolumn{4}{|c|}{$\begin{array}{l}\text { Stickiness Parameter } \lambda \text { : } \\
\text { Including the Financial Crisis Period }\end{array}$} \\
\hline $\begin{array}{l}\text { Truncation } \\
\text { at lag: }\end{array}$ & 3 & 4 & 5 & 6 & 3 & 4 & 5 & 6 \\
\hline$\alpha=0.10$ & $\begin{array}{l}0.312 \\
(5.27)^{* * *}\end{array}$ & $\begin{array}{l}0.309 \\
(7.26)^{* * *}\end{array}$ & $\begin{array}{l}0.295 \\
(5.73)^{* * *}\end{array}$ & $\begin{array}{l}0.292 \\
(5.20)^{* * *}\end{array}$ & $\begin{array}{l}0.620 \\
(8.26)^{* * *}\end{array}$ & $\begin{array}{l}0.612 \\
(7.19)^{* * *}\end{array}$ & $\begin{array}{l}0.585 \\
(6.40)^{* * *}\end{array}$ & $\begin{array}{l}0.575 \\
(6.08)^{* * * *}\end{array}$ \\
\hline$\alpha=0.15$ & $\begin{array}{l}0.305 \\
(3.14)^{* *}\end{array}$ & $\begin{array}{l}0.297 \\
(6.21)^{* * *}\end{array}$ & $\begin{array}{l}0.295 \\
(4.75)^{* * *}\end{array}$ & $\begin{array}{l}0.290 \\
(4.21)^{* * *}\end{array}$ & $\begin{array}{l}0.617 \\
(5.09)^{* * *}\end{array}$ & $\begin{array}{l}0.608 \\
(6.32)^{* * *}\end{array}$ & $\begin{array}{l}0.606 \\
(6.26)^{* * *}\end{array}$ & $\begin{array}{l}0.597 \\
(6.00)^{* * *}\end{array}$ \\
\hline$\alpha=0.20$ & $\begin{array}{l}0.307 \\
(7.83)^{* * *}\end{array}$ & $\begin{array}{l}0.302 \\
(5.46)^{* * *}\end{array}$ & $\begin{array}{l}0.300 \\
(6.74)^{* * *}\end{array}$ & $\begin{array}{l}0.298 \\
(5.69)^{* * *}\end{array}$ & $\begin{array}{l}0.623 \\
(5.11)^{* * *}\end{array}$ & $\begin{array}{l}0.617 \\
(6.74)^{* * *}\end{array}$ & $\begin{array}{l}0.610 \\
(4.40)^{* * *}\end{array}$ & $\begin{array}{l}0.602 \\
(4.65)^{* * *}\end{array}$ \\
\hline $\begin{array}{l}\text { Dummies } \\
\text { Included }\end{array}$ & \multicolumn{4}{|c|}{ DUM1982; DUM1991; DUM2O01 } & \multicolumn{4}{|c|}{ DUM1982; DUM1991; DUM2001; DUMFC } \\
\hline $\begin{array}{l}\text { Time } \\
\text { Period }\end{array}$ & \multicolumn{4}{|c|}{ 1978.Q1-2006.Q4 } & \multicolumn{4}{|c|}{ 1978.Q1-2011.Q4 } \\
\hline
\end{tabular}

Notes: See Table 2.

Results show that all the coefficients are statistically significant at the conventional levels. Prior to the financial crisis, $\lambda$ was around 0.3 . However, when the sample is extended to include the financial crisis period, the estimates of $\lambda$ have increased to around 0.6 , implying that 
around $60 \%$ of firms use updated information in their pricing decisions. For each estimated equation, the $\chi^{2}$ summary statistics indicate that there is no serial correlation, functional form misspecification, non-normality and heteroscedasticity in the residuals; these results are not reported for brevity.

\section{Sequential Estimation of $\lambda$}

In what follows, we estimate $\lambda$ by adding a quarter sequentially from 2007.Q1 to 2011.Q4. This sequential estimation reveals the exact time when the estimate of $\lambda$ starts to increase during the crisis. We first construct 20 samples such as 1978.Q1-2007.Q1, 1978.Q1- 2007.Q2,..,1978.Q12011.Q3 and 1978.Q1-2011.Q4. For each sample, we consider truncation at lags 3 to 6 and $\alpha$ values of $0.10,0.15$ and 0.20 . Using the SUR method, we perform 240 estimations for $\lambda$. The HP filtered output gap is employed. The NLLS method gave consistent results to SUR and these are not reported for brevity. The dummy variables used are DUM1982, DUM1991, DUM2001 and DUMFC. Note that the latter dummy is adjusted accordingly as the sample size increases.

Figures 1 to 3 illustrate the estimates of $\lambda$ for 20 samples. For comparability purpose, we also include the estimates of $\lambda$ from sample 1978.Q1-2006.Q4. We find that the $\lambda$ coefficients are statistically significant at the conventional levels in all samples. These results imply that $\lambda$ is high during the financial crisis period compared to the pre-crisis period. Looking closely, $\lambda$ values appeared in a somewhat humped shape or inverted $U$ pattern. When the samples are extended up to 2007.Q4, $\lambda$ increased to around 0.5 . The rapid increase in $\lambda$ is observed until the sample 1978.Q1-2009.Q2. The highest value of $\lambda$ is around 0.8 and this is observed in the periods when the crisis was severe.

Beyond the sample 1978.Q1-2009.Q2, $\lambda$ started to decline. Perhaps this is because the crisis was a bit relaxed in 2010 and 2011. Although $\lambda$ diminished beyond this period, it is still higher than the pre-crisis period. Moreover, the behavior of $\lambda$ is consistent in all three Figures. In other words, truncation at lags 3 to 6 and $\alpha$ values of $0.10,0.15$ and 0.20 yield consistent results. The diagnostic issues such as serial correlation, functional form misspecification and heteroscedasticity are satisfactory in all equations. ${ }^{1}$ In the case of non- normality in the residuals, it is rejected at $15 \%$ level in some equations.

\footnotetext{
${ }^{1}$ These results are not reported for brevity.
} 


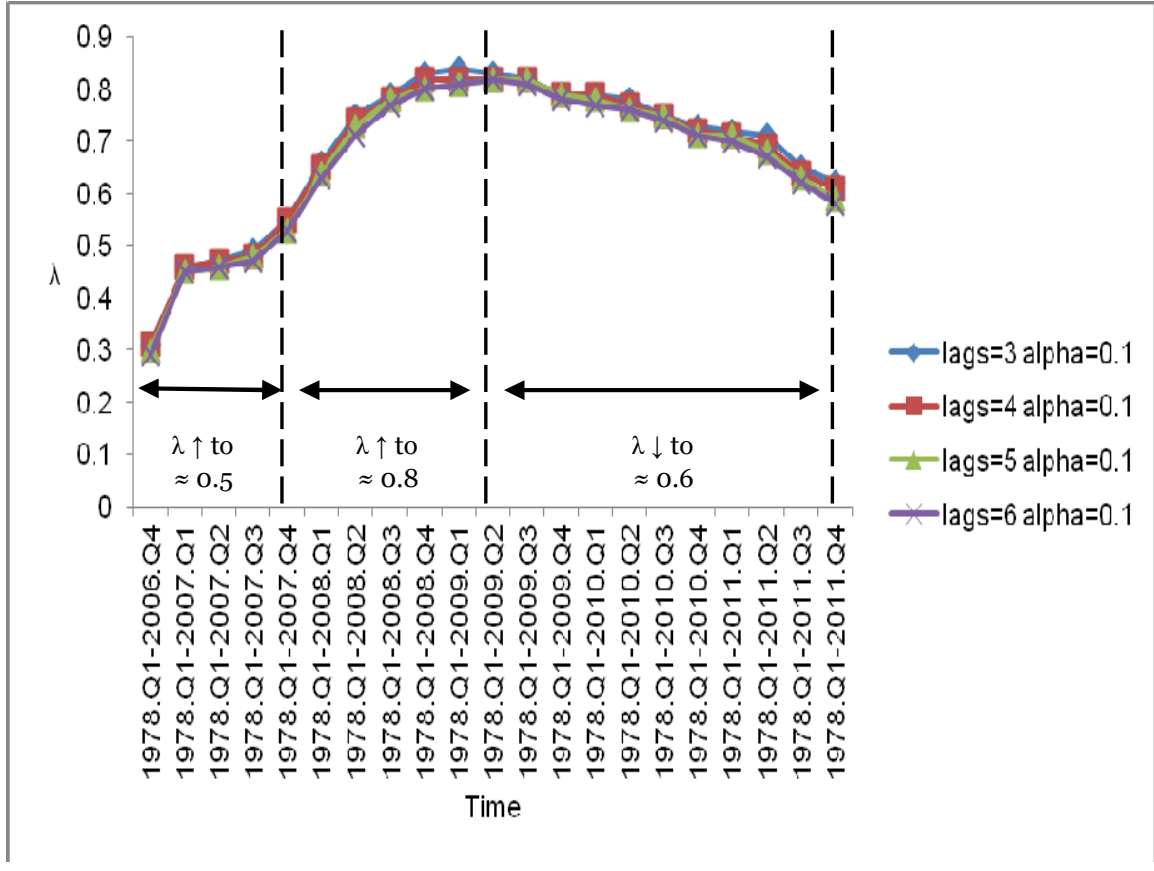

Figure 1: Estimates of $\lambda$ when truncation at lags $=3$ to 6 and alpha $=0.1$

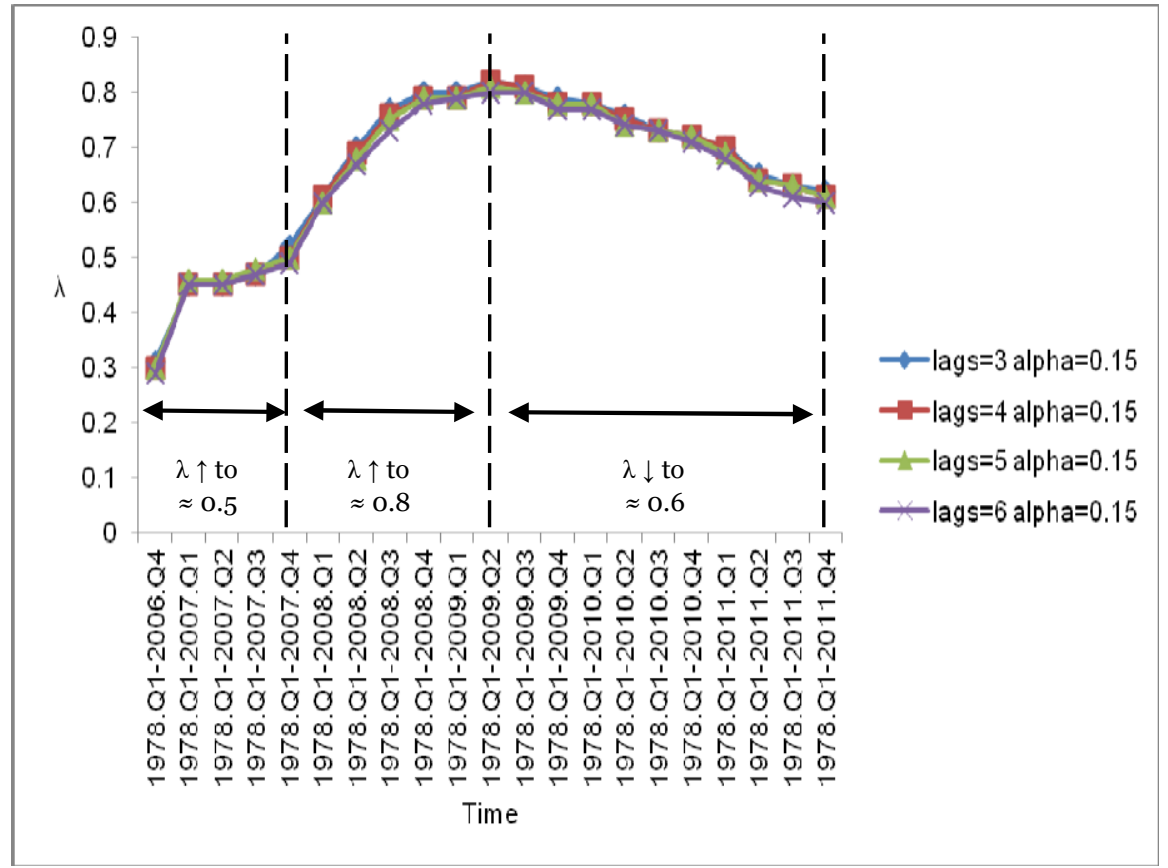

Figure 2: Estimates of $\lambda$ when truncation at lags $=3$ to 6 and alpha $=0.15$ 


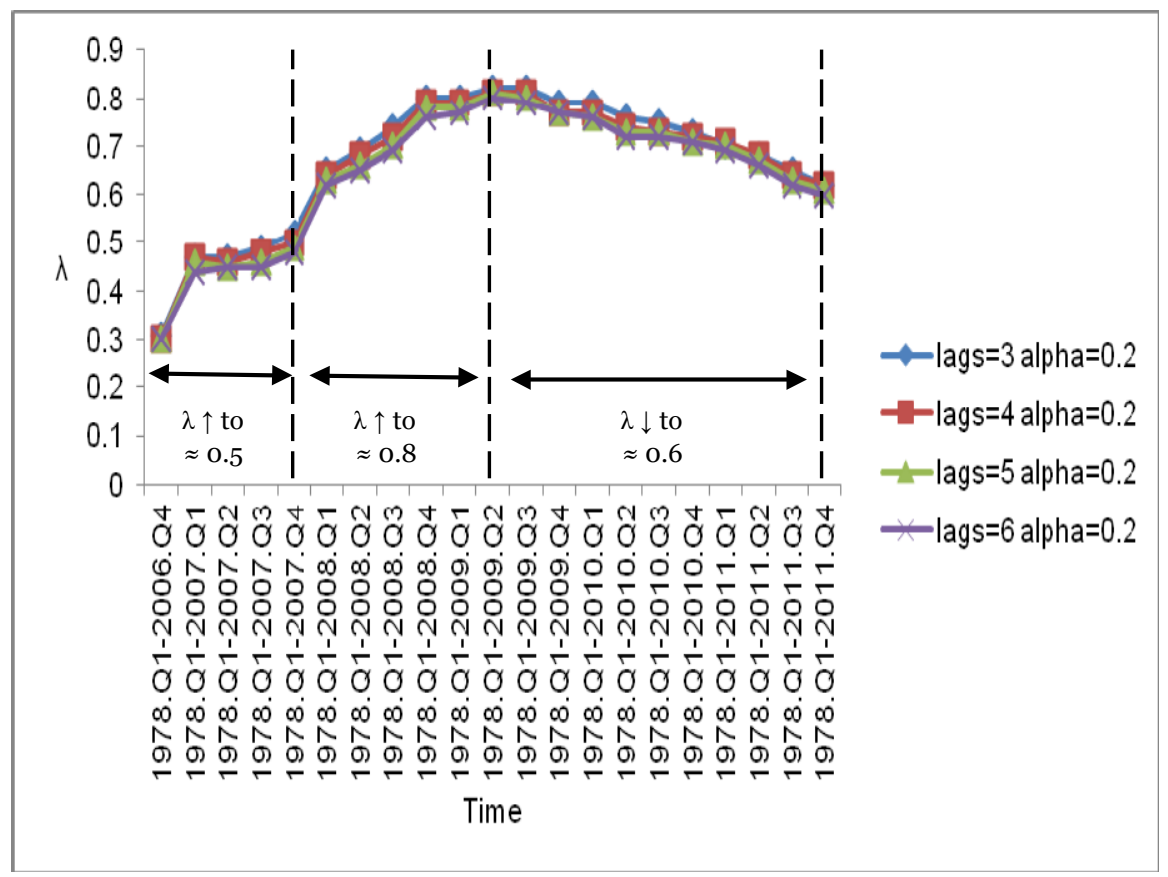

Figure 3: Estimates of $\lambda$ when truncation at lags $=3$ to 6 and alpha $=0.2$

Our results imply that during the periods of uncertainty more firms become flexible and use updated information to set optimal prices. This is possibly due to the availability of macroeconomic news. The media coverage about the macroeconomy is always widespread during a financial crisis. Economic agents receive macroeconomic information from media very frequently and such information is helpful in their decision making (Abad and Chulia, 2014).

\section{A Comparison with Other Studies}

Our estimate of $\lambda$ close to 0.3 (prior to the financial crisis) is consistent with those of Mankiw and Reis (2003), Carroll (2003), Khan and Zhu (2006) and Korenok (2008) for the USA and Dopke et al. (2008a, 2008b) for the European countries. Mankiw and Reis (2003) developed an SIPC which relates inflation to employment and productivity. They find an estimate of 0.25 for $\lambda$. Carroll (2003) investigated the evolution of household inflation expectations and find $\lambda$ is 0.27 . Khan and Zhu (2006) considered the finite forecasting horizons to construct past forecasts of inflation and output gap. They attained an average $\lambda$ value of 0.24 . Analogously, Korenok (2008) and Kiley (2007) also proxy for inflation expectations. While Korenok's (2008) estimates are consistent with ours, Kiley (2007) attained fairly high estimates between 0.44 and 0.71 . Dopke et al. (2008a, 2008b) estimated the SIPC similar to Mankiw and Reis (2002) and find $\lambda$ is around 
0.3 in France, Germany and the UK. For Italy, they find $\lambda$ is between 0.5 and 0.6. Our contribution in this literature is that we unveil the empirical evidence on the behavior of information stickiness in the 2007-08 financial crisis period.

\section{Robustness Check}

The widely used HP filter is a highpass filter, removing the trend and returning high frequency components in business cycle component. Recently it was demonstrated by Cogley and Nason (1995) that the HP filter is likely to generate spurious cyclical structure at business cycle frequencies in the presence of difference stationary series. We confirm robustness of our results by using the BK and CF filtering methods. In contrast to the HP filter, the BK filter is a bandpass filter which allows suppression of both the low frequency trend components and the high frequency components in an economic series. $\mathrm{CF}$ discuss optimal finite-sample approximations to the ideal bandpass filter, including one-sided filters that can be used in real time. They find that imposing stationary and symmetric weights on the approximation problem is usually inappropriate. They compare their random walk (RW) filter to the BK filter and find that the RW filter dominates in terms of an optimality criterion. Unlike the BK filter, no observations are lost by the RW filter.

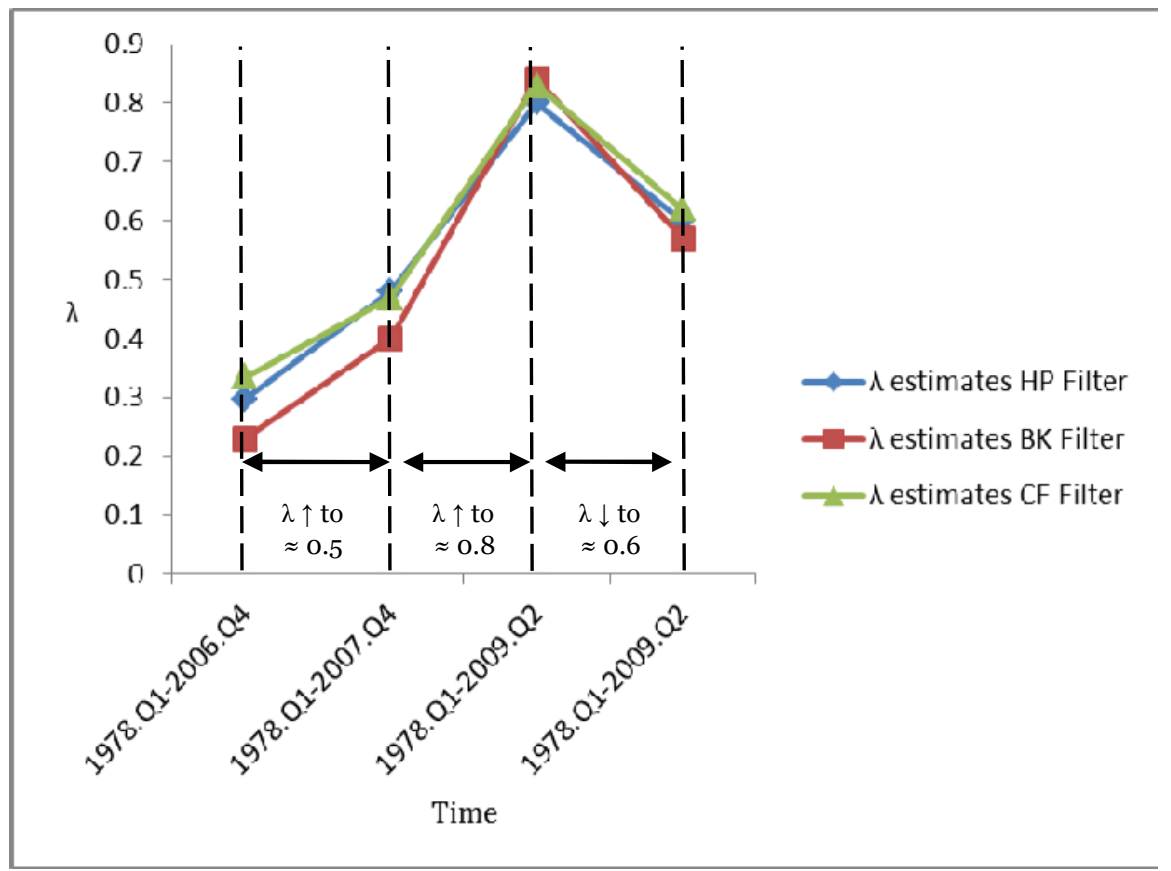

Figure 4: Estimates of $\lambda$ using HP, BK and CF filtering 
We filter cycles in the band from 1.5 to 8 years and use $k=12$ for the lead and lag lengths as recommended by BK (1999) and CF (2003). Figure 4 illustrates the SUR estimates of $\lambda$ when the output gap is computed using the HP, BK and CF filtering methods. We perform estimations for four periods 1978.Q1-2006.Q4 ( $\lambda$ in pre-crisis), 1978.Q1-2007.Q4 ( $\lambda$ at beginning of the crisis), 1978.Q1-2009.Q2 ( $\lambda$ at peak of the crisis) and 1978.Q12011.Q4 ( $\lambda$ for whole period) using truncation at lag $=6$ and $\alpha=0.2 .^{2}$ The dummy variables used are DUM1982, DUM1991, DUM2001 and DUMFC. ${ }^{3}$ We find that $\lambda$ estimates are fairly consistent with HP and CF filters. They show that estimates of $\lambda$ increased during the financial crisis period. The BK filter produced a similar pattern but the $\lambda$ estimates are slightly lower in the samples 1978.Q1-2006.Q4 and 1978.Q1- 2007.Q4. In all cases, the values of $\lambda$ are statistically significant at the conventional levels and the diagnostic tests are satisfactory.

\section{Conclusion}

This paper utilizes quarterly data over the period 1978.Q1-2011.Q4 to estimate the information stickiness parameter $\lambda$ for the USA. In doing so, we use the nonlinear least squares (NLLS) and seemingly unrelated regression (SUR) techniques. We first test for the integrated order of the variables using the Carrion-i-Silvestre et al. (2009) technique. Then, we estimate $\lambda$ over two sample periods: prior to the crisis (1978.Q1-2006.Q4) and including the crisis (1978.Q12011.Q4). In addition, we estimate $\lambda$ by adding a quarter sequentially from 2007.Q1 to 2011.Q4 to precisely determine when this parameter starts to change during the crisis period. The output gap is computed using the Hodrick-Prescott (1997) method. For the purpose of robustness, we also apply Baxter and King (1999) and Christiano and Fitzgerald (2003) methods.

The test results of Carrion-i-Silvestre et al. (2009) point to trend stationary processes in inflation and output gap. Most break dates depicted by this test correspond to the recent financial crisis. The NLLS and SUR produced fairly consistent results. We find that prior to the financial crisis, $\lambda$ was around 0.3 . However, when the sample is extended to include the financial crisis period, $\lambda$ increased to around 0.6. The estimate of $\lambda$ until 2007.Q4 was around 0.5, however it rapidly increased to around 0.8 when the sample is extended up to 2009.Q2. Samples beyond 2009.Q2 reveal that $\lambda$ started to decline, though still higher than the estimate in pre-crisis period.

\footnotetext{
${ }^{2}$ Other truncation lags $(3,4$ and 5$)$ and values $(0.1$ and 0.15$)$ gave similar estimates of $\lambda$. These results are not reported for brevity.

${ }^{3}$ DUMFC is adjusted accordingly as the sample period increase.
} 
These results show that $\lambda$ values appeared in a somewhat humped shape or inverted $U$ pattern during the financial crisis. Overall, these results imply that during the recent financial crisis many firms became flexible and efficient and used updated information to set optimal prices. 
Compliance with Ethical Standards:

(In case of Funding) Funding: This study was funded by X (grant number X). No funding received.

Conflict of Interest: Author A has received research grants from Company A. Author B has received a speaker honorarium from Company $X$ and owns stock in Company $Y$. Author $C$ is a member of committee Z. OR if no conflict exists: Author A declares that he/she has no conflict of interest. Author B declares that he/she has no conflict of interest. ... Saten Kumar declares no conflict of interest.

(In case animals were involved) Ethical approval : All applicable international, national, and/or institutional guidelines for the care and use of animals were followed. Not applicable.

(And/or in case humans were involved) Ethical approval: All procedures performed in studies involving human participants were in accordance with the ethical standards of the institutional and/or national research committee and with the 1964 Helsinki declaration and its later amendments or comparable ethical standards. Not applicable.

(If articles do not contain studies with human participants or animals by any of the authors, please select one of the following statements) Ethical approval: This article does not contain any studies with human participants performed by any of the authors. 


\section{References}

Abad, P. and Chulia, H. (2014) "The effects of macroeconomic news announcements during the global financial crisis, in Jonathan A. Batten, Niklas F. Wagner (ed.) Risk management post financial crisis: A period of monetary easing (Contemporary Studies in Economic and Financial Analysis, Volume 96) Emerald Group Publishing Limited, 41 - 56.

Arslan, M.M. (2010) "Relative importance of sticky prices and sticky information in price setting," Economic Modelling, 39, 127-154.

Ball, L. and Romer, D. (1990) "Real rigidities and the nonneutrality of money," Review of Economic Studies, 57, 539-552.

Baxter, M. and King, R. (1999) "Measuring business cycles; Approximate bandpass filters for economic time series," Review of Economics and Statistics, 81, 575-593.

Carrera, C. (2012) "Estimating information rigidity using firms' survey data," Working Paper No. 4, Banco Central de Reserva del Perú.

Carrion-i-Silvestre, J.L., Kim, D. and Perron, P. (2009) "GLS-based unit root tests with multiple structural breaks under both the null and the alternative hypotheses," Econometric Theory, 25, 1754-1792.

Carroll, C. D. (2003) "Macroeconomic expectations of households and professional forecasters," Quarterly Journal of Economics, 118, 269-298.

Christiano, L.J. and Fitzgerald, T.J. (2003) “The band pass filter," International Economic Review, 44, 435-465.

Cogley, T. and Nason, J.M. (1995) "Effects of the Hodrick-Prescott filter on trend and difference stationary time series: Implications for business cycle research," Journal of Economic Dynamics and Control, 19, 253-278.

Coibion, O. (2010) “Testing the sticky information Phillips curve," Journal of Money, Credit and Banking, 92, 87-101.

Dopke, J., Dovern, J., Fritsche, U. and Slacalek, J. (2008a) "The dynamics of European inflation expectations," The B.E. Journal of Macroeconomics, 8, Article 12.

(2008b) "Sticky information Phillips curves: European evidence,"Journal of Money, Credit and Banking, 40, 1513-1520. 
Elliott, G., Rothenberg, T.J. and Stock, J.H. (1996) "Efficient tests for an autoregressive unit root," Econometrica, 64, 813-836.

Hodrick, R. and Prescott, E. (1997) "Postwar U.S. business cycles: An empirical investigation," Empirical Economics, 19, 493-500.

Khan, H., Zhu, Z. (2006) "Estimates of the sticky-information Phillips curve for the United States," Journal of Money, Credit, and Banking, 38, 195- 207.

Kiley, M.T (2007) "A quantitative comparison of sticky-price and sticky-information models of price setting," Journal of Money, Credit and Banking, 39, 101-125.

Klenow, P.J., and Willis, J.L. (2007) "Sticky information and sticky prices," Journal of Monetary Economics, 54, 79-99.

Korenok, O. (2008) "Empirical comparison of sticky price and sticky information models," Journal of Macroeconomics, 30, 906-927.

Laforte, J-P. (2007) "Pricing models: A Bayesian DSGE approach for the U.S. economy," Journal of Money, Credit and Banking, 39, 127-154.

Mankiw, N. G. and Reis, R. (2002) "Sticky information versus sticky prices: A proposal to replace the New Keynesian Phillips curve," Quarterly Journal of Economics, 117, 12951328.

(2003) "Sticky information: A model of monetary non-neutrality and structural slumps," in Knowledge, Information, and Expectation in Modern Macroeconomics, ed. by P. Aghion, pp. 64-86, Cambridge, MA. MIT Press. (2006) "Pervasive stickiness," American Economic Review, 96(2), 164 169.

Ng, S. and Perron, P. (2001) "Lag length selection and the construction of unit root tests with good size and power," Econometrica, 69, 1519-1554.

Pickering, A. (2004) "Sticky information and the Phillips Curve - A tale of two forecasts," Manuscript, University of Bristol.

Stock, J.H. (1999) "A class of tests for integration and cointegration," in Cointegration, Causality, and Forecasting: A Festschrift for Clive W.J. Granger, pp. 135-167. Oxford University Press. 